\title{
Correlation Between Morphological Properties and Ionic Conductivity in an Electrolyte Based on Poly(Vinylidene Fluoride) and Poly (2-Hydroxyethyl Methacrylate)
}

\author{
Lívio Bruno J. S. ${ }^{\text {**, Patrícia S. de O. Patricio }}{ }^{\mathrm{b}}$,Tulio Matencio ${ }^{\mathrm{c}}$, Rodrigo L. Oréfice ${ }^{\mathrm{a}}$
}

\author{
${ }^{a}$ Departamento de Engenharia Metalúrgica e de Materiais, Universidade de Federal de Minas \\ Gerais - UFMG, Av. Antônio Carlos, 6627, Pampulha, CEP 31270-901, Belo Horizonte, MG, Brasil \\ ${ }^{\mathrm{b}}$ Centro Federal de Educação Tecnológica de Minas Gerais - CEFET-MG, \\ Av. Amazonas, 5253, CEP 30421-169, Belo Horizonte, MG, Brasil \\ ${ }^{\mathrm{C}}$ Departamento de Química, Universidade Federal de Minas Gerais - UFMG, \\ Av. Antônio Carlos, 6627, Pampulha, CEP 31270-901, Belo Horizonte, MG, Brasil
}

Received: January 14, 2013; Revised: August 26, 2013

\begin{abstract}
Materials based on a mixture of poly(vinylidene fluoride) (PVDF), poly(2-hydroxyethyl methacrylate) (PHEMA) and $\mathrm{LiClO}_{4}$ were produced to evaluate their ionic behavior and morphological structure to determine if they can be used as an electrolyte in electrical devices. FTIR chemical analysis results indicated the presence of interactions between PVDF, PHEMA and $\mathrm{LiClO}_{4}$. MDSC results showed that the transition temperatures of the polymers shifted to higher temperatures for systems containing high concentrations of each polymer. SEM images indicated that there was some miscibility between the polymers especially for the 25 and $75 \mathrm{wt}$. \% compositions. In terms of the electrical performance, the ionic conductivity level of the electrolyte could be controlled by changing the composition of the system.
\end{abstract}

Keywords: blends, differential scanning calorimeter, electrolytes

\section{Introduction}

Polymer electrolytes are important for technology because they can be used in the fabrication of special devices, such as electrochromic ${ }^{1,2}$ devices, lithium batteries $^{3-5}$, supercapacitors ${ }^{6}$, sensors ${ }^{7,8}$, and fuel cell polymer electrolyte membranes (PEM $)^{9-11}$. A large number of materials have been tested in this area, but conducting polymers and gel polymer electrolytes stand out.

Solid polymer electrolytes (SPE) are frequently studied for advanced uses ${ }^{12,13}$. The considerable interest in this type of material is due to the large variety of applications for which it can be used, such as electrochromic devices ${ }^{14}$, ion-batteries, ion selective membranes ${ }^{15,16}$, and sensors ${ }^{17,18}$. For this type of electrolyte, the use of hydrogels is very interesting because they can be easily manipulated and synthesized; the main reason that ions are easily transported through their backbones is because of their porosity and amorphous structure. They are also electrochemically stable, and their byproducts are not combustible. These properties are very beneficial for the performance of batteries, supercapacitors, and fuel cells ${ }^{19}$. A hydrogel electrolyte must also have favorable mechanical properties and be compatible with the electrodes. To have these characteristics, the materials need to be very homogenous. One of the strategies used to obtain the desired characteristics is to prepare polymer blends with added salts so that they have a good balance between conductivity and SPE composition.

Baskaran et al..$^{18}$ studied the effect of the variation in the composition of poly(vinyl acetate)/poly(vinylidene

*e-mail: liviolivon@gmail.com fluoride) blends containing lithium perchlorate $\left(\mathrm{LiClO}_{4}\right)$ on the ionic conductivity of this SPE. Electrolyte relaxation was discussed in terms of impedance and dielectric analysis. Rajendran et al. ${ }^{20}$ verified the effect of $\mathrm{LiClO}_{4}$ and $\mathrm{LiBF}_{4}$ salt concentration in blends of PVDF/PVC maintaining a composition $^{20}$ of $80 / 20$ wt. $\%$.

Performance tests of poly(2-hydroxyethyl methacrylate) and poly(vinylidene fluoride) are presented in this study. Although other hydrogels have been tested with PVDF, there is no information on the use of a poly(2-hydroxyethyl methacrylate) (PHEMA) hydrogel electrolyte in this type of application. The PHEMA hydrogel has already been used for the transfer of ions in biological studies, the mobilization and transfer of biomolecules using this ion mobility ${ }^{21}$, and frequently, for the selection and separation of ions in solution ${ }^{22,23}$; PHEMA has not yet been used in the study of ion-generated potential energy.

In this work, hydrogel polymer electrolytes were produced. The polymers were poly(2-hydroxyethyl methacrylate), PHEMA, and poly(vinylidene fluoride), PVDF. Electrolytes were prepared with different compositions of PVDF and PHEMA and a specific concentration of $\mathrm{LiClO}_{4}$ to determine the relationship between their structural properties, morphologies, thermal properties, and conductivities. Fourier-Transform Infrared Spectroscopy (FTIR), Modulated Temperature Differential Scanning Calorimetry (MDSC), Scanning Electron Microscopy (SEM), and Impedance Spectroscopy (IS) were used to characterize the materials at different structural 
levels. PVDF is used in fuel cells ${ }^{24,25}$ and battery systems ${ }^{26,27}$, and PHEMA has biomedical ${ }^{28}$, polymer electrolyte ${ }^{29}$, and other applications.

\section{Experimental}

2-hydroxyethyl methacrylate, $\mathrm{LiClO}_{4}(99 \%)$, and 4,4'azobis(4-cyanovaleric acid) were acquired from Aldrich. Poly(vinylidene fluoride) $\left(\mathrm{M}_{\mathrm{w}}=8.0 \times 10^{4} \mathrm{Da}\right)$ was purchased from Polyscience. Dimethylformamide was purchase from Synth.

PHEMA was synthesized by combining an ethyl alcohol solution of 2.5 wt. $\%$ and 4,4'azobis(4-cyanovaleric acid) initiator in a two-neck flask which contained $4 \mathrm{~mL}$ of 2 -hydroxyethyl methacrylate, HEMA (97\%) dissolved in $40 \mathrm{~mL}$ of ethanol. The reaction medium was stirred rapidly with a magnetic stir plate for 2 hours at $80{ }^{\circ} \mathrm{C}$. Next, the solution was stirred slowly under a dynamic vacuum for 15 minutes to evaporate the solvent. After the solvent had been evaporated, the PHEMA was placed in a petri dish and dried in a desiccator under a dynamic vacuum for 48 hours. After that, the dry polymer was macerated to a fine grain size so that it could be used easily.

PHEMA/PVDF and $\mathrm{LiClO}_{4}$ electrolytes were prepared for casting using dimethylformamide (DMF 99.7\%) as a solvent. The ranges of $\mathrm{PHEMA} / \mathrm{PVDF} / \mathrm{LiClO}_{4}$ were $90 / 0 / 10$, $75 / 15 / 10,50 / 40 / 10$ or $25 / 65 / 10$ wt. \%. PHEMA, PVDF (98.5\%) and $\mathrm{LiClO}_{4}$ were completely dissolved in DMF with slow stirring at $60{ }^{\circ} \mathrm{C}$ for 15 minutes. The solutions were cast in silicone molds and dried at $45{ }^{\circ} \mathrm{C}$ for one week.

A Perkin Elmer 1000 spectrophotometer equipped with a horizontal attenuated reflection (ATR) accessory was used to take Fourier transform infrared measurements of the sample. The spectra of the samples were obtained in the region from 4000 to $500 \mathrm{~cm}^{-1}$ using a ZnSe crystal.

Thermal analyses were performed in a TA Instruments MDSC 2920 using approximately $9 \mathrm{mg}$ of each sample placed in an aluminum recipient, which was then purged with helium gas at $40 \mathrm{~mL} / \mathrm{min}$. An initial run was performed to erase the thermal history of the samples. A second run was made from -140 to $180{ }^{\circ} \mathrm{C}$ at a heating rate of $3{ }^{\circ} \mathrm{C} / \mathrm{min}$ with an amplitude modulation of $1^{\circ} \mathrm{C}$ for 60 seconds.

The morphological study of the PVDF/PHEMA electrolytes and neat polymers was carried out with a JEOL model 6360LV scanning electron microscope (SEM) operating at $15 \mathrm{kV}$. The samples were immersed in liquid nitrogen and were broken.

An AutoLab PG100/FRA was used for impedance spectroscopy. The frequency range was $1 \times 10^{-2} \mathrm{~Hz}-1 \times 10^{5} \mathrm{~Hz}$ and the perturbation potential was $10 \mathrm{mV}$. All measurements were performed at $\sim 25^{\circ} \mathrm{C}$. The electrolyte disk samples (10 $\mathrm{mm}$ diameter, $3 \mathrm{~mm}$ thick) were sandwiched between two stainless steel disks.

\section{Results and Discussion}

Figure 1 shows the FTIR spectra of PVDF/PHEMA electrolyte containing $0,25,50,75$ wt. \% PVDF and pure PVDF for comparison. The characteristic absorption bands of PVDF were observed at approximately 1632, 1410 and $1238 \mathrm{~cm}^{-1}$ and were associated with $\mathrm{C}=\mathrm{C}, \mathrm{C}-\mathrm{F}$ stretching vibration mode and $\mathrm{C}-\mathrm{F}_{2}$ bending, respectively. There were also bands at 867 and $836 \mathrm{~cm}^{-1}$ associated with $\mathrm{CF}-\mathrm{CH}$ - $\mathrm{CH}$ backbone stretching vibrations present in the PVDF structure. For PHEMA, there were profile bands at $3400-3100,1710,1150$ and $1022 \mathrm{~cm}^{-1}$ corresponding to $\mathrm{O}-\mathrm{H}, \mathrm{C}=\mathrm{O}, \mathrm{C}-\mathrm{C}-\mathrm{O}$ group stretching vibrations and $\mathrm{O}-\mathrm{H}$ bending, respectively. Free $\mathrm{C}=\mathrm{O}$ groups with a maximum intensity at approximately $1730 \mathrm{~cm}^{-1}$ contribute to the carbonyl band of polyacrylate and the ones involved in hydrogen bonding interactions appear at lower frequencies.

FTIR spectra of the electrolytes prepared with these polymers had bands related to the vibrations of groups present in both PVDF and PHEMA. Generally, typical bands of PVDF were more prominent in the PVDF/ PHEMA/LiClO $45 / 15 / 10$ and 50/40/10 electrolytes than in the $25 / 65 / 10$. On the other hand, in electrolytes with a 50 wt. \% PVDF content, an inversion of the relative intensity was observed between the 1022 and $1150 \mathrm{~cm}^{-1}$ bands, unlike electrolytes with 75 wt. \% PVDF. This fact can be attributed to the high intensity of the band in the spectrum of PHEMA, which became more pronounced in the PVDF/PHEMA/LiClO 4 25/65/10 system. However, in the FTIR spectrum of PHEMA, a shoulder can be observed at approximately $1000 \mathrm{~cm}^{-1}$, which is more intense compared to the highest frequency one in the same band. This region, approximately $1000-1200 \mathrm{~cm}^{-1}$, is very important to the $\mathrm{PVDF} / \mathrm{LiClO}_{4}$ system because of the characteristic formation of coordination complexes of the salt with $\mathrm{CF}_{2}$ moieties in $\mathrm{PVDF}^{30}$. The change in the relative intensities of the bands in the FTIR spectrum of the electrolyte with added PHEMA was influenced by the complexes formed between the lithium salt and the PVDF. The hydroxyl group of PHEMA is possibly involved in hydrogen bonding interactions with the fluoride atom of PVDF, which includes hydrogen atoms or preferential interactions with the $\mathrm{Li}^{+}$salt cations and oxygen atoms.

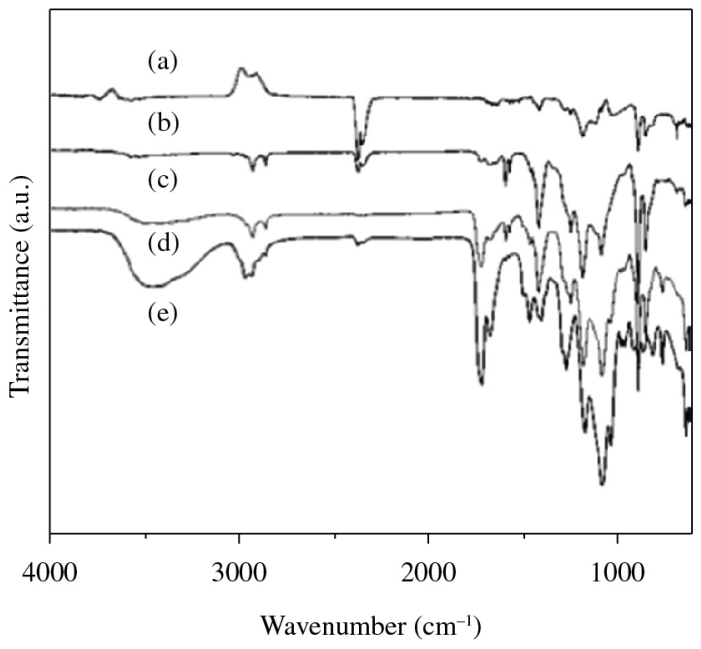

Figure 1. FTIR of neat polymer (a) PVDF and (e) PHEMA and electrolytes PVDF PHEMA/LiClO 4 : (b) $(75 / 15 / 10)$, (c) (50/40/10) and (d) $(25 / 65 / 10)$. 
Thermal analysis using a modulated differential scanning calorimeter (MDSC) was carried out to observe the change in transition temperature $\left(\mathrm{T}_{\mathrm{g}}\right)$ that is caused by adding PHEMA to the electrolyte. Figure 2 shows the MDSC curves obtained for the following polymer electrolytes: PVDF/LiClO 4 90/10 and PVDF/PHEMA/LiClO 4 75/15/10 and 25/65/10. The MDSC curves have one glass transition temperature for all of the systems. The glass transition temperature $\left(\mathrm{T}_{\mathrm{g}}\right)$ of $\mathrm{PVDF} / \mathrm{LiClO}_{4}$ was obtained through heat capacity curves using the first derivate at approximately

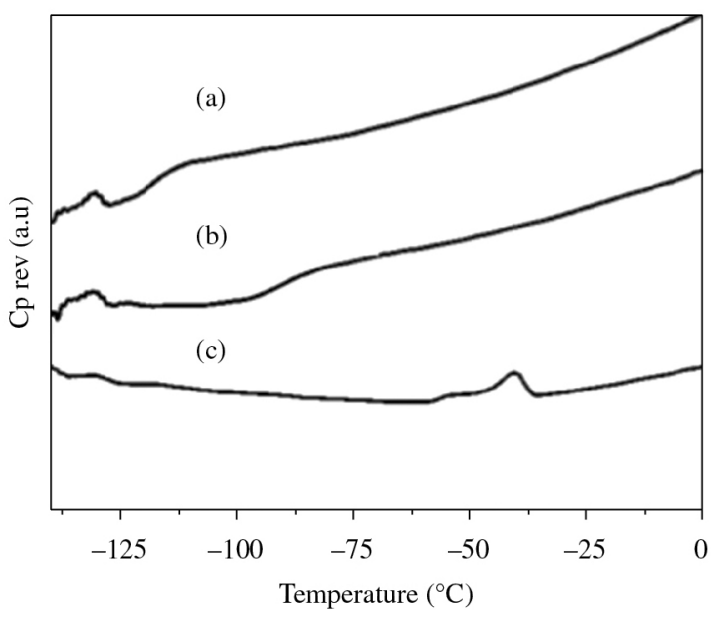

Figure 2. MDSC curves of electrolytes containing PVDF/ $\mathrm{LiClO}_{4}(90 / 10)$ (a), PVDF PHEMA/LiClO 4 (25/65/10) (b) and $(75 / 15 / 10)(c)$.
$-110{ }^{\circ} \mathrm{C}$. In other works, authors identified a higher $\mathrm{T}$, possibly because of the plasticizer effect caused by the salt, as has been reported ${ }^{18}$. It was not possible to identify the glass transition of PHEMA. Sanchez et al. ${ }^{31}$ identified only the glass transition of the expanded gel in the experimental DSC on heating. The event observed at $-40^{\circ} \mathrm{C}$ in the MDSC curve of PVDF/PHEMA/LiClO 4 25/65/10 electrolyte, which has a high concentration of PHEMA, is typical of polymer hydrogels and occurred at temperatures near the glass transition. This endothermic event is associated with the existence of different states of water sorbed in the hydrogels. The MDSC thermal investigation illustrated this event better than conventional DSC.

A significant shift in $\mathrm{T}_{\mathrm{g}}$ to higher temperatures can be observed when comparing the curves of electrolytes containing 25 and 75 wt. \% PHEMA and the samples without PHEMA. The presence of PHEMA gives the electrolytes the characteristics of rigid materials. The glass transition of the electrolytes shifts towards the PHEMA endothermic event, as has been described previously. Moreover, the shift of $\mathrm{T}_{\mathrm{g}}$ clearly indicates some degree of miscibility between the polymers in the electrolyte. In the MDSC curve of 75 wt. \% PVDF (75/15/10), $\mathrm{T}_{\mathrm{g}}$ was very close to $-108{ }^{\circ} \mathrm{C}$ - the $\mathrm{T}_{\mathrm{g}}$ of pure PVDF. The interaction suggested by the IR spectra could be responsible for the partial miscibility of the polymers.

Figure 3 shows scanning electron microscopy (SEM) images obtained of the fracture surfaces of the PVDF (a), PVDF/PHEMA/LiClO 4 (25/65/10) (b), (50/45/10) (c), (75/15/10) (d) and pure PHEMA (e) electrolytes with range composition. The pure PVDF film was highly porous and had a cluster-like morphology with primary

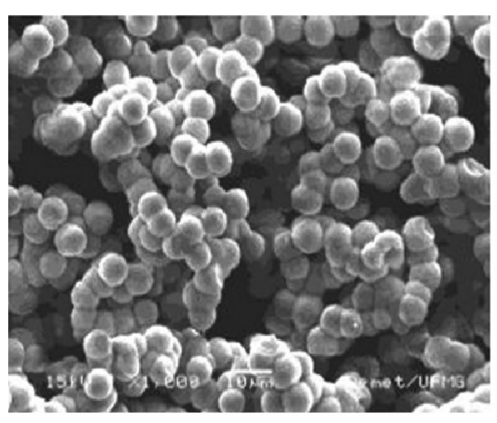

(a)

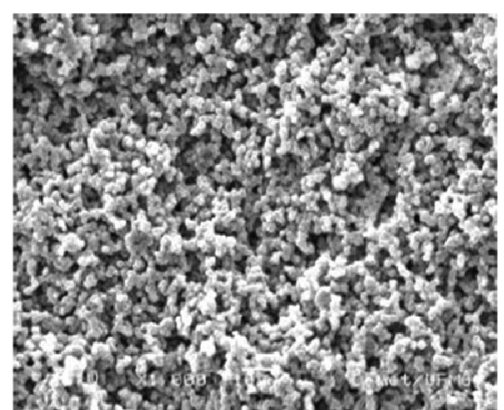

(b)

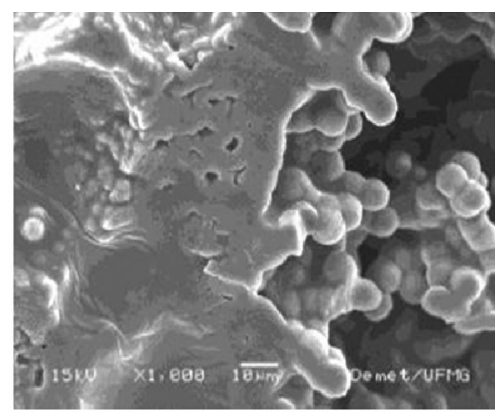

(c)

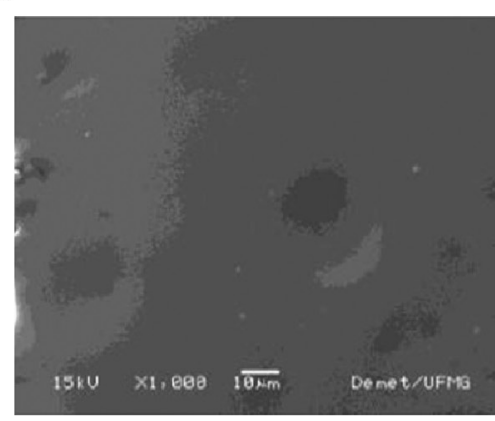

(d)

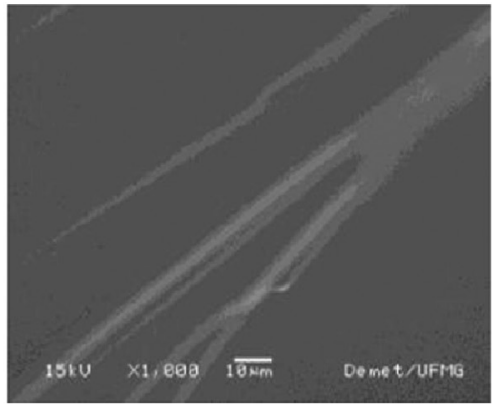

(e)

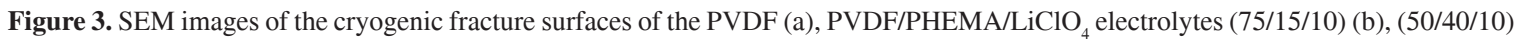
(c), (25/65/10) (d), and PHEMA (e). 


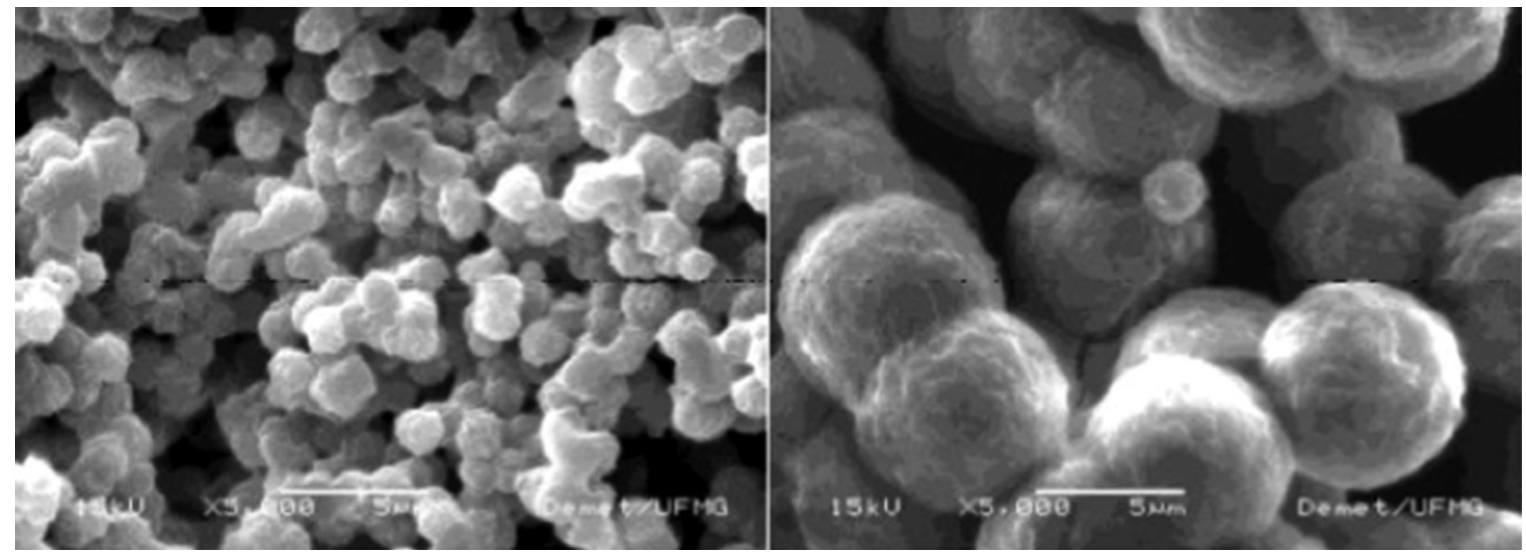

Figure 4. Fracture images of materials higher magnification of PVDF (left) and PVDF/PHEMA/LiClO ${ }_{4}(75 / 15 / 10)$ (right).

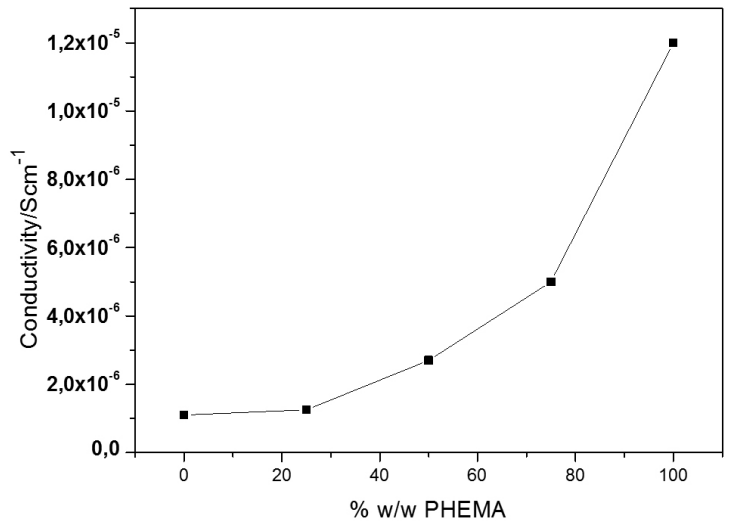

Figure 5. Curve of ionic conductivity of samples neat polymer and polymer electrolyte.

particles, as shown in Figure 3a. PVDF clusters have a regular morphology similar to spheres. The addition of 25 wt. \% PHEMA to the samples reduced the porosity and decreased the size of the domains, see Figure $3 \mathrm{~b}$. The average spheroid size of the domains was estimated using SEM images with high magnification, Figure $4 a, b$. In the case of PVDF, average sphere size was approximately $5 \mu \mathrm{m}$ and for electrolyte it is nearly $2 \mu \mathrm{m}$.

When the concentration of PHEMA was high, the morphology of the electrolyte was modified substantially, see Figure 3c, d. The electrolyte with 50 wt. \% PVDF had a heterogeneous fracture with two phases: (i) a continuous phase rich in PHEMA and (ii) a dispersed phase similar to the clusters typically observed in images of PVDF, Figure 3c. Spherical domains were homogenous along the length of the samples. This difference from the others samples suggests a lower level of miscibility for this specific composition. Figure 3d shows the SEM images of the samples with $25 \mathrm{wt} \%$ PVDF. These samples had only one phase, which was similar to pure PHEMA electrolyte, as seen in Figure 3e.
Ionic conductivity of the electrolytes could be controlled by varying the concentrations of each polymer in the materials. Conductivity was higher with greater PHEMA concentrations in the samples because the ionic conductivity depends on the level of crystallinity, amorphous phase, and molecular mobility. PVDF is a polymer with a high level of crystallinity, and PHEMA is an amorphous polymer. The ionic conductivity increases when the amorphous part is larger than the crystalline part. Thus, the larger the amorphous part is, the higher the ionic conductivity will be. In terms of the mobility of the Li ions, PHEMA also offers $\mathrm{OH}$ and $\mathrm{C}=\mathrm{O}$ polar groups in its structure that favor the mobility of the ions that produce the ionic current. Therefore, a large amount of PHEMA is important to reach high levels of ionic conductivity, as observed in Figure 5.

\section{Conclusions}

Electrolytes containing pure poly(vinylidene fluoride) (PVDF) or poly(2-hydroxylethyl methacrylate) (PHEMA) and mixtures of the polymers with a range of concentrations were prepared with added $\mathrm{LiClO}_{4}$. The results of the structural (FTIR), thermal (MDSC), morphological analyses (SEM), and measurements of the electrical properties (IS) confirmed that there are polymer interactions in the materials. The electrolyte containing $50 \mathrm{wt}$. \% of each polymer had the lowest miscibility of the studied materials. An increase in the ionic conductivity was observed for materials with higher concentrations of PHEMA despite the concentration of salt. This is due to the larger amount of amorphous polymer that favors ion conductivity of the electrolytes. Therefore, the ratio between the crystalline and amorphous structure of the materials was a main factor that can be used to tailor their ionic conductivity.

\section{Acknowledgments}

The authors would like to thank CNPq (MCT/EDT No 62/2008) for financial support. 


\section{References}

1. Zeng Q, McNally A, Keyes TE and Forster RJ. Redox induced switching dynamics of a three colour electrochromic metallopolymer film. Electrochimica Acta. 2008; 53(25):70338. http://dx.doi.org/10.1016/j.electacta.2008.05.027

2. Chen YC, Wang CM, Wen CY and Shih TY. Study of $\mathrm{MoO}_{3}-\mathrm{NiO}$ complementary electrochromic devices using a gel polymer electrolyte. Solid State Ionics. 2012; 212:81-7. http://dx.doi.org/10.1016/j.ssi.2012.02.005

3. Liao YH, Rao MM, Li WS, Yang LT, Zhu BK, Xu R et al. Fumed silica-doped poly(butyl methacrylate-styrene)-based gel polymer electrolyte for lithium ion battery. Journal of Membrane Science. 2010; 352:95-9. http://dx.doi. org/10.1016/j.memsci.2010.01.064

4. Wang HL, Shu LP and Jiang ST. Preparation of Poly(lactic acid)/Poly(methyl methacrylate)/Silicon Dioxide Degradable Hybrid Electrolytes. Journal of applied polymer science. 2010; 117:2790-4. http://dx.doi.org/10.1002/ app.31935

5. Morten W, Guk-Tae K, Mario J, Martin W and Stefano P. Temperature dependence of electrochemical properties of cross-linked poly(ethylene oxide)lithium bis(trifluoromethanesulfonyl)imide- $N$-butyl- $N$ methylpyrrolidinium bis(trifluoromethanesulfonyl)imide solid polymer electrolytes for lithium batteries. Electrochimica Acta. 2013;87:779-87. http://dx.doi.org/10.1016/j. electacta.2012.09.034

6. Rodríguez J, Navarrete E, Dalchiele EA, Sánchez L, Barrado JRR and Martín F. Polyvinylpyrrolidone and $\mathrm{LiClO}_{4}$ solid polymer electrolyte and its application in transparent thin film supercapacitors. Journal of Power Sources. 2013;237:270-6. http://dx.doi.org/10.1016/j.jpowsour.2013.03.043

7. Oprea A, Courbat J, Bârsan N, Briand D, De Rooij NF and Weimara U. Temperature, humidity and gas sensors integrated on plastic foil for low power applications. Sensors and Actuators B: Chemical. 2009; 140:227-32. http://dx.doi. org/10.1016/j.snb.2009.04.019

8. Bhambare KS, Gupta S, Mench MM and Ray A. A carbon monoxide sensor in polymer electrolyte fuel cells based on symbolic dynamic filtering. Sensors and Actuators B. 2008; 134:803-15. http://dx.doi.org/10.1016/j. snb.2008.06.057

9. Takahashi S, Okonogi H, Hagiwara T and Maekawa Y. Preparation of polymer electrolyte membranes consisting of alkyl sulfonic acid for a fuel cell using radiation grafting and subsequent substitution/elimination reactions. Journal of Membrane Science. 2008; 324:173-80. http://dx.doi. org/10.1016/j.memsci.2008.07.012

10. Srouji AK, Zheng LJ, Dross R, Turhan A and Mench MM. Ultra-high current density water management in polymer electrolyte fuel cell with porous metallic flow field. Journal of Power Sources. 2013; 239:433-42. http://dx.doi.org/10.1016/j. jpowsour.2013.03.145

11. Yang X, Liu Y, Fang Y, Wang L, Li S and Wei X. A direct methanol fuel cell without the use of a polymer electrolyte membrane or precious metal cathode catalyst. Journal of Power Sources. 2013; 234:272-6. http://dx.doi.org/10.1016/j. jpowsour.2013.01.176

12. Helen M, Viswanathan B and Srinivasa MS. Poly(vinyl alcohol)polyacrylamide blends with cesium salts of heteropolyacid as a polymer electrolyte for direct methanol fuel cell applications. Journal Applied Polymer Science. 2010; 116:3437-47. http:// dx.doi.org/10.1002/app.31940
13. Yang Y, Tao J, Jin J and Qin Q. New Microporous Polymer Electrolyte Based on Polysiloxane Grafted with Imidazolium IodideMoieties for DSSC. International Journal of Photoenergy. 2011; Article ID 405738. http://dx.doi. org/10.1155/2011/405738

14. Barbosa PC, Rodrigues LC, Silva MM, Smith MJ, Parola AJ, Pina F et al. Solid-state electrochromic devices using pTMC/PEO blends as polymer electrolytes. Electrochimica Acta. 2010; 55:1495-1502. http://dx.doi.org/10.1016/j. electacta.2009.03.031

15. Szpakowska M, Marjanska E and Lisowska-Oleksiak A. Investigation of sour substances by a set of all-solid-state membrane electrodes. Desalination. 2009; 241:236-43. http:// dx.doi.org/10.1016/j.desal.2007.12.052

16. Peng M-J, Guo Y, Yang X-F, Wang L-Y and An J. A highly selective ratiometric and colorimetric chemosensor for cyanide detection. Dyes and Pigments. 2013; 98:327-32. http://dx.doi. org/10.1016/j.dyepig.2013.03.024

17. Palaniappan S, Sydulu SB and Srinivas P. Synthesis of copolymer of aniline and pyrrole by inverted emulsion polymerization method for supercapacitor. Journal Applied Polymer Science. 2010; 115(3):1695-1701. http://dx.doi. org/10.1002/app.31208

18. Baskaran R, Selvasekarapandian S, Kuwata N, Kawamura J and Hattori T. ac impedance, DSC and FT-IR investigations on (x)PVAc- $(1-x) \mathrm{PVdF}$ blends with $\mathrm{LiClO}_{4}$. Materials Chemistry and Physics. 2006; 98:55-61. http://dx.doi.org/10.1016/j. matchemphys.2005.08.063

19. Chavez E, Oviedo-Roa LR, Contreras-Pérez G, Magadán JM and Alvarado FLC. Theoretical studies of ionic conductivity of crosslinked chitosan membranes. International Journal of Hydrogen Energy. 2010; 35:12141-6. http://dx.doi. org/10.1016/j.ijhydene.2009.06.083

20. Rajendran S, Sivakumar $P$ and Babu RS. Studies on the salt concentration of a PVdF-PVC based polymer blend electrolyte. Journal Power Sources. 2007; 164:815-21. http://dx.doi. org/10.1016/j.jpowsour.2006.09.011

21. Özgür E, Bereli N, Türkmen D, Ünal S and Denizli A. PHEMA cryogel for in-vitro removal of anti-dsDNA antibodies from SLE plasma. Materials Science and Engineering: C 2011;31:91520. http://dx.doi.org/10.1016/j.msec.2011.02.012

22. Akkaya R and Ulusoy U. Tl-208, Pb-212, Bi-212, Ra-226 and Ac-228 adsorption onto polyhydroxyethylmethacrylatebentonite composite. Nuclear Instruments and Methods in Physics Research A. 2012; 664:98-102. http://dx.doi. org/10.1016/j.nima.2011.10.037

23. Moradi O, Aghaie M, Zare K, Monajjemi M and Aghaie H. The study of adsorption characteristics $\mathrm{Cu}^{2+}$ and $\mathrm{Pb}^{2+}$ ions onto PHEMA and P(MMA-HEMA) surfaces from aqueous single solution. Journal of Hazardous Materials. 2009;170:673-9. PMid:19497662. http://dx.doi. org/10.1016/j.jhazmat.2009.05.012

24. Ong AL, Bottino A, Capannelli G and Comite A. Effect of preparative parameters on the characteristic of poly(vinylidene fluoride)-based microporous layer for proton exchange membrane fuel cells. Journal of Power Sources. 2008; 183:628. http://dx.doi.org/10.1016/j.jpowsour.2008.04.064

25. Pandey $\mathrm{J}$ and Shukla A. Synthesis and characterization of PVDF supported silica immobilized phosphotungstic acid (Si-PWA/PVDF) ion exchange membrane. Material Letters. 2013;100:292-5. http://dx.doi.org/10.1016/j. matlet.2013.03.039

26. Chen Z, Christensen L and Dahn JR. Study of the mechanical and electrical properties of carbon/poly(vinylidene fluoride- 
tetrafluoroethylene- propylene) films crosslinked with triethylenetetramine: Possible application as binder for lithium-ion battery electrodes. Journal of Applied Polymer Science. 2004; 91(5):2949-57. http://dx.doi.org/10.1002/ app. 13504

27. Miao R, Liu B, Zhu Z, Liu Y, Li J, Wang X et al. PVDF-HFPbased porous polymer electrolyte membranes for lithium-ion batteries. Journal of Power Source. 2008; 184:420-6. http:// dx.doi.org/10.1016/j.jpowsour.2008.03.045

28. Santos JR, Couceiro R, Concheiro A, Torres-Labandeira JJ and Alvarez-Lorenzo C. Poly(hydroxyethyl methacrylateco-methacrylated- $\beta$-cyclodextrin) hydrogels: Synthesis, cytocompatibility, mechanical properties and drug loading/ release properties. Acta Biomaterialia. 2008; 4:745-
55. PMid:18291738. http://dx.doi.org/10.1016/j. actbio.2007.12.008

29. Reiter J, Velická J and Míka M. Proton-conducting polymer electrolytes based on methacrylates. Electrochimica Acta. 2008; 53:7769-74. http://dx.doi.org/10.1016/j. electacta.2008.05.066

30. Shen YJ, Reddy MJ and Chu PPJ. Porous PVDF with $\mathrm{LiClO}_{4}$ complex as solid and wet polymer electrolyte impedance. Solid State Ionics. 2004; 175:747-50. http://dx.doi.org/10.1016/j. ssi.2003.10.020

31. Sanchez MS, Pradas MM and Ribelles JLG. Thermal transitions in PHEA hydrogels by thermomechanical analysis. A comparison with DSC data. European Polymer Journal 2004; 40:329-34. http://dx.doi.org/10.1016/j. eurpolymj.2003.09.021 